\title{
Gender effect on coronary angiographic findings in evaluation of chest pain
}

\author{
Ismail D. Saeed ${ }^{\mathrm{a}}$, Majid A. Abdulmajeed ${ }^{\mathrm{b}}$ \\ From the a Department of Medicine, College of Medicine, University of Mosul, ${ }^{b}$ Department of Medicine, Ibn Sina Teaching \\ Hospital, Mosul, Iraq. \\ Correspondence: Ismail D. Saeed ${ }^{\mathrm{a}}$. ismael_dawoud@yahoo.com. \\ (Ann Coll Med Mosul 2013; 39 (2): 147-153). \\ Received: 31 ${ }^{\text {st }}$ Oct. 2012; Accepted: $20^{\text {th }}$ Mar. 2013.
}

\begin{abstract}
Objective: The primary objective of this study is to evaluate the effect of gender on angiographic findings in referred patients with chest pain and to study the gender-related differences in risk factors in patients with coronary artery disease as a secondary goal.
\end{abstract}

Design: A retrospective, clinical study of 230 patients with chest pain.

Setting: Mosul Heart Center - Ibn Sina Teaching Hospital.

Patients and methods: From Sept. $1^{\text {st }} 2011$ to Jan. $31^{\text {st }} 2012$, a total of 230 (100 female, 130 male) patients with chest pain who underwent diagnostic coronary angiography in Mosul Heart Center - Ibn Sina Teaching Hospital were studied retrospectively. Both the whole female population and post-menopausal females as a separate group was compared with a whole male population depending on the presence or absence of coronary artery disease identified by coronary angiography. The main outcome of cardiovascular risk factors: hypertension, diabetes mellitus, hypercholesterolemia, smoking and family history of coronary heart disease were also studied in relation to the gender.

Results: The correlation between the whole female and male populations with positive coronary angiography: $59 \%(59 / 100)$ vs. $89.2 \%(116 / 130)$ respectively, was statistically significant $(p<0.001)$. The correlation between post-menopausal women and whole male population with positive coronary angiography: $67.14 \%(47 / 70)$ vs. $89.2 \%(116 / 130)$ was also statistically significant $(p<0.05)$.

The mean age $(\mathrm{yr}) \pm \mathrm{SD}$ of whole female population with positive coronary angiography was (57.48 \pm 8.8$)$, while it was $(53.34 \pm 9.0)$ for male population with positive coronary angiographic findings. The correlation was statistically significant $(p<0.01)$. The mean age $(y r) \pm S D$ of post-menopausal females with positive results was $(59: 14 \pm 7.04)$. This was also statistically significant in comparison with main age of whole male population $(p<0.01)$. Hypertension and family history of ischemic heart disease were more prevalent in females than in males with coronary heart disease, $30(50.8 \%)$ and $41(69.4 \%)$ versus $44(37.9 \%)$ and 60 $(51.7 \%)$ respectively, this was statistically significant $(p<0.05)$.

Conclusions: Females with chest pain who were referred for diagnostic coronary angiography had significantly more negative angiography test than males, and the mean age of females with positive test is significantly higher than males. Hypertension and family history of ischemic heart disease were more prevalent in females with coronary artery disease than in males.

Keywords: Coronary artery disease (CAD), coronary angiography, gender effect on coronary angiography.

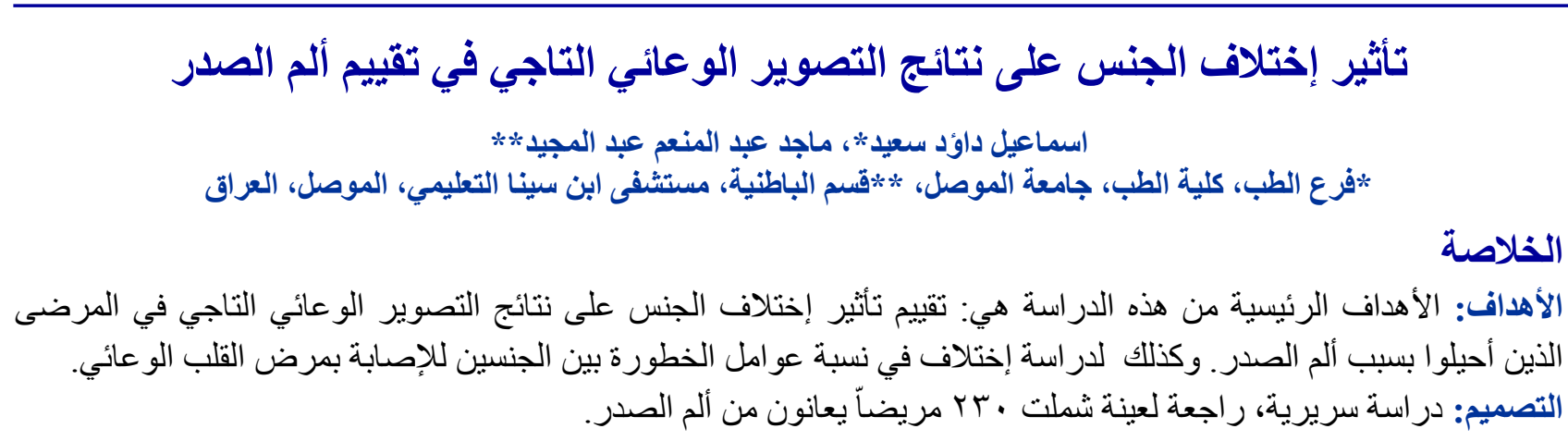


الموقع: مركز الموصل للقلب في مستشفى ابن سينا التعليمي.

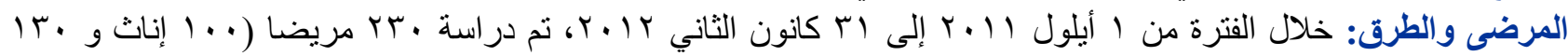

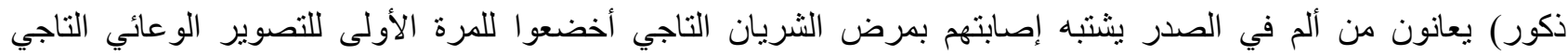

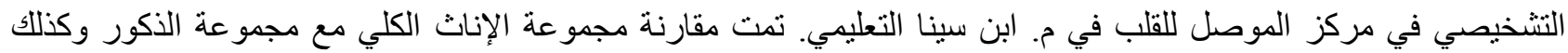

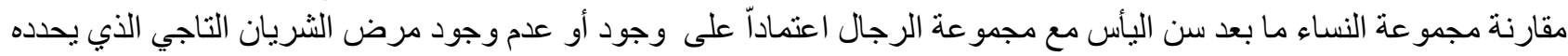

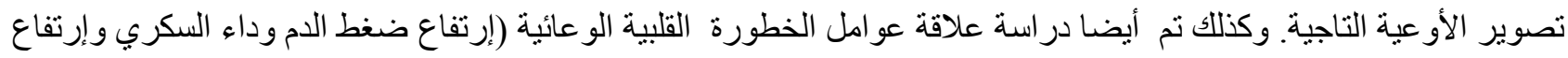

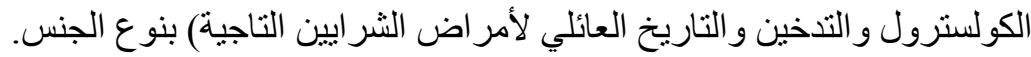

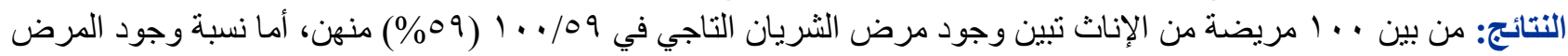

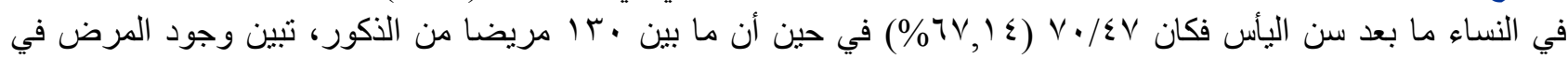

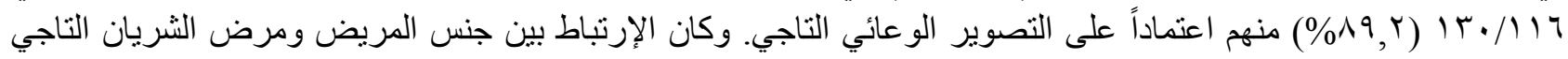

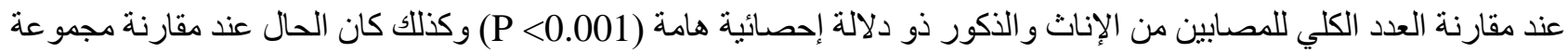

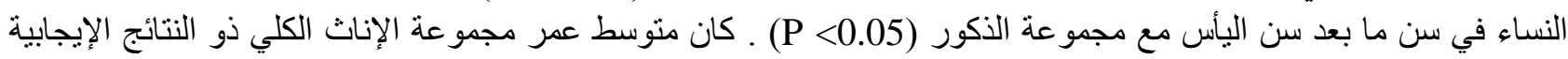

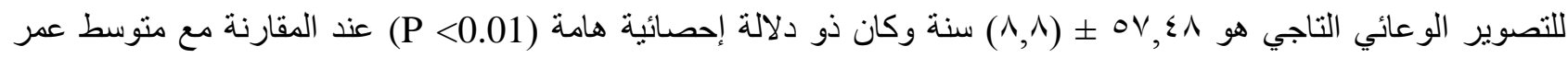

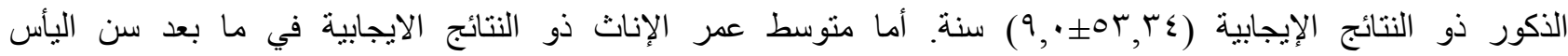

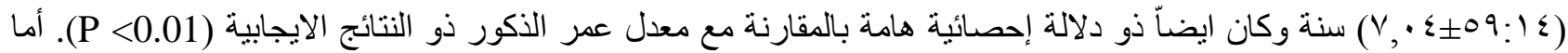

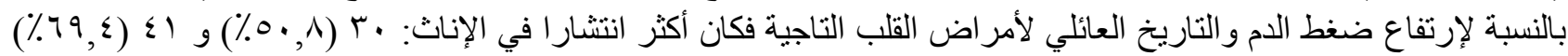

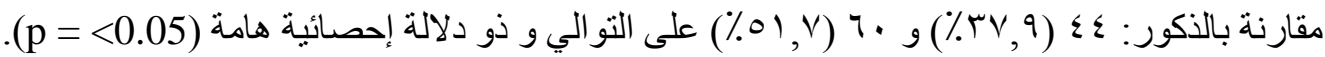

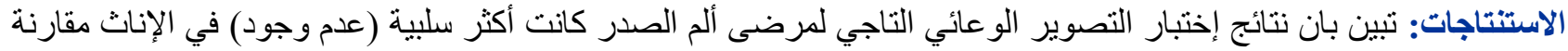

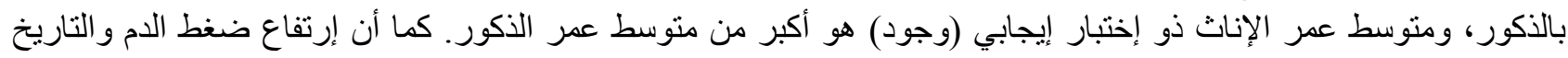

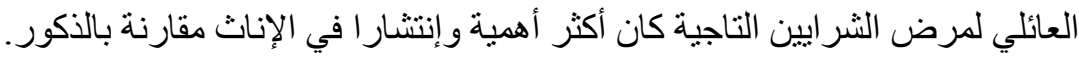

\section{INTRODUCTION}

C oronary artery disease (CAD) is the most common form of heart disease and the single most important cause of death. By 2020 it is estimated that it will be the major cause of death in all regions of the world. ${ }^{1}$ The clinical syndromes of coronary artery disease are overwhelmingly the result of underlying atherosclerosis of the epicardial coronary arteries. This process is present to some degree at almost all ages and in both men and women. ${ }^{2}$ The main clinical presentation of coronary artery disease is chest pain. The two commonly described pain syndromes are stable angina pectoris and acute coronary syndrome. The latter includes unstable angina and acute myocardial infarction (AMI). Coronary artery disease in women is a leading cause of mortality and disability, and important differences exist in symptoms, diagnostic test characteristics, and outcome compared with men. ${ }^{3}$ Chest pain in women is a commonly encountered condition which accounts for an appreciable number of referrals to cardiologists for further evaluation. ${ }^{4}$ The symptom of chest pain has many causes which may or may not be cardiac in origin, and difficulty arises in establishing whether or not the patient's symptoms can be ascribed to reversible myocardial ischaemia. Coronary angiography is the criterion for establishing a diagnosis of coronary artery disease. The reasons for referral for cardiac investigation are multifactorial and generally take into account the severity of the symptoms and the perceived likelihood of coronary artery disease. For example, increasing age and the presence of several recognized risk factors for coronary artery disease would tend to lower the threshold for referral. Patients with positive results on an exercise test are more likely to be further investigated, but ST segment down shift with exercise is a less specific marker of coronary artery disease in women., Many patients referred with chest pain for investigation undergo coronary angiography. However coronary angiography carries a small but well documented risk of complications and consequently should be reserved for those patients most likely to have chest pain of cardiac origin. ${ }^{7}$ Traditional cardiovascular risk factors are overall similar in women and men and across various 
regions of the world. However, the increased risk associated with hypertension and diabetes and the protective effect of exercise and alcohol appear to be somewhat larger in women than in men., Collectively, nine potentially modifiable risk factors (smoking, hypertension, diabetes, waist/hip ratio, dietary patterns, physical activity, consumption of alcohol, plasma apolipoproteins, and psychosocial factors) account for $94 \%$ of the population attributable risk of $\mathrm{AMI}$ in women and $90 \%$ in men. ${ }^{8}$ For young women with favourable levels of all five major risk factors (smoking, hypertension, diabetes, serum cholesterol and body mass index), CAD and other cardiovascular disease (CVD) are rare events. ${ }^{9}$ Unfortunately, only about $20 \%$ of women younger than 40 years of age meet these low-risk criteria and $48 \%$ of women have a clustering of three or more metabolic risk factors for CAD. ${ }^{10}$

The primary goal of the present study is to evaluate the effect of gender on coronary angiography finding as an endpoint diagnostic tool. In addition we studied the differences in some risk factors between genders as a secondary goal in people with chest pain.

\section{PATIENTS AND METHODS}

This study was approved by the Scientific Research Committee at the College of Medicine, University of Mosul. Formal consent of the involved sample of patients was already taken after explanation of procedure to them. We studied retrospectively a total of 230 patients (age range 33-76 years; mean age, $55.12 \pm 9.11$ years). The sample consists of $43.48 \%$ (100/230) female, with mean age, (54.84 \pm 9.27 years) and $56.52 \%$ $(130 / 230)$ males, with mean age, $(53.04 \pm 8.57$ years), who underwent the first diagnostic coronary angiography for suspicion of CAD in Mosul Heart Center - Ibn Sina Teaching Hospital, during a period from September 1st 2011 to January 31st 2012. All female and male patients were compared regarding the presence or absence of coronary artery disease identified by coronary angiography. In addition, the post-menopausal females as a separate group were compared with the male group. The different risk factors for CAD in each group with positive coronary angiography were also compared.

\section{Pre-angiographic data collection}

The main sources of date collection were: Clinical: which included patient demographics, risk factors: family history of ischaemic heart disease (first degree relative with coronary artery disease), hypercholesterolemia: (random total cholesterol $>6.5 \mathrm{mmol} / \mathrm{l}$ or patient receiving lipid lowering agent), hypertension requiring specific treatment, history of smoking whether current or previous cigarette smoker, diabetes mellitus requiring treatment (by diet, oral hypoglycaemics, or insulin), and symptom status suggestive of myocardial ischaemia. Full clinical examination, in particular those related to cardiovascular system was performed. Blood tests: for haemoglobin concentration, blood sugar, lipid profiles and other tests according to individual requirements. Noninvasive specific tests: These included electrocardiography (ECG), exercise stress test and echocardiography. Review of previous patient's reports: clinical and investigatory reports.

\section{Coronary angiography study}

For the purpose of the primary analysis after taking in consideration the indications, and contraindications for the procedure; a selective elective coronary angiography in multiple views along left ventriculography using Siemens cardangiography machine model 2003 was performed by standard technique to define coronary lesions and ventricular function. According to a strategy applied at Mosul Heart Center, we defined the significant obstructive $\mathrm{CAD}$ as the presence of at least $70 \%$ (in some other schools $50 \%$ ) reduction in diameter of one or more of major epicardial coronary arteries: Right coronary artery (RCA), left anterior descending artery (LAD) and left circumflex (LCX) or at least $50 \%$ reduction in diameter of left main stem artery. ${ }^{11}$ Normal angiography was considered when the test did not identify any obstruction in major epicardial coronary arteries. The character of lesions was defined as diffuse by the presence of more than one significant lesion in the coronary artery or if the obstruction lesion was more than $(10 \mathrm{~mm})$ in length.

\section{Statistical analysis}

The data has been processed and analyzed by using software of statistical package for Social 
Science (SPSS). All variables were expressed as a number and percent and compared using Fisher's exact test when appropriate. The mean value \pm standard deviation (SD) was calculated for age variable of the patient in year, a $p$-value $\leq 0.05$ was regarded as the limit of statistical significant.

\section{RESULTS}

A total of 230 patients with an age range (33-76 years) and mean age of $(55.12 \pm 9.11$ years $)$ were studied. Females were $43.48 \%(100 / 230)$ and the mean age was (54:84 $\pm 9: 27$ years), while $56.52 \%$ $(130 / 230)$ were males, and the mean age was (53.04 \pm 8.57 years).

Among female group of patients referred with chest pain for diagnostic coronary angiography, $59 \%(59 / 100)$ with mean age: (57.49 \pm 8.80 years) had CAD (positive coronary angiography). Premenopausal females (mean age: $44.48 \pm 4.58$ years) formed $20.33 \%(12 / 59)$ of angiography positive female population, while postmenopausal females (mean age: 59:14 \pm 7.04 years) formed $79.66 \%$ (47/59) of angiography positive female population. Among 130 male patients, $89.20 \%$ (116/130) with mean age: (53.34 \pm 9.0 years) had coronary artery disease (positive angiography). The correlation between whole females and males regarding the percentage of positive coronary angiography ( $59 \%$ vs. $89.20 \%$ with $p<0.001)$ and between their mean age $(57.48 \pm 8.8$ years vs. $53.34 \pm 9.0$ with $p<0.01$ ) was statistically significant. (Table 1).

This was also applied to correlation between post-menopausal female as a separate group and the whole male population with CAD (positive coronary angiography); for both the percentage of positive test and mean age: $(79.66 \%$ vs. $89.20 \%$ with $p<0.05)$ and $(59: 14 \pm 7.04$ years vs. $53.34 \pm$ 9.0 years with $p<0.01$ ) respectively. Table 2 .

Hypertension and family history of coronary artery disease were more prevalent in females than in males with CAD (positive coronary angiography) $30(50.85 \%)$ and $41(69.49 \%)$, vs. 38 $(32.76 \%)$ and $60(51.72 \%)$ respectively. This was statistically significant $p<0.05$. Table 3 .

The differences in the prevalence of hypercholesterolemia, diabetes mellitus and smoking were statistically not significant between females and males who had CAD (positive coronary angiography test): 21 (35.59\%), 10 $(16.94 \%)$ and $35(59.32 \%)$ vs. $44(37.93 \%), 15$ (12.93\%) and 67(57.76\%) respectively. Table 3.

Table 1. Comparison between total females and males populations regarding coronary angiographic finding.

\begin{tabular}{|c|c|c|c|c|c|c|}
\hline $\begin{array}{l}\text { Gender } \\
\text { (total) }\end{array}$ & $\begin{array}{c}\text { Positive } \\
\text { angiography } \\
\mathrm{N}(\%)\end{array}$ & $\begin{array}{c}\text { Negative } \\
\text { angiography } \\
\mathrm{N}(\%)\end{array}$ & $\begin{array}{l}\text { Total } \\
\text { N (\%) }\end{array}$ & P-Value & Mean age \pm SD & $\begin{array}{c}\text { P. } \\
\text { Value }\end{array}$ \\
\hline Females & $59 / 100(59)$ & $41 / 100(41)$ & $100(43.5)$ & \multirow{3}{*}{$<0.001$} & $57.49 \pm 8.8$ & \multirow{3}{*}{$<0.01$} \\
\hline Males & $116 / 130(89.2)$ & 14/130 (10.8) & $130(56.5)$ & & $53.34 \pm 9.0$ & \\
\hline Total & $175(76.1)$ & $55(23.9)$ & $230(100)$ & & $55.12 \pm 9.11$ & \\
\hline
\end{tabular}

Table 2. Comparison between postmenopausal women as a separate group and whole men population, regarding coronary angiographic finding.

\begin{tabular}{lcccccc}
\hline \multicolumn{1}{c}{ Gender } & $\begin{array}{c}\text { Positive } \\
\text { angiography } \\
\mathbf{N}(\%)\end{array}$ & $\begin{array}{c}\text { Negative } \\
\text { angiography } \\
\mathbf{N}(\%)\end{array}$ & $\begin{array}{c}\text { Total } \\
\mathbf{N}(\%)\end{array}$ & $\begin{array}{c}\text { P- } \\
\text { Value }\end{array}$ & Mean age \pm SD & $\begin{array}{c}\text { P- } \\
\text { Value }\end{array}$ \\
\hline $\begin{array}{l}\text { Postmenopausal } \\
\text { Females }(\mathrm{n} 70)\end{array}$ & $47 / 70(67.14)$ & $23 / 70(32.86)$ & $70(35)$ & $<0.05$ & $59: 14 \pm 7.04$ & $<0.01$ \\
Males $(\mathrm{n} \mathrm{130)}$ & $116 / 130(89.20)$ & $14 / 130(10.8)$ & $130(65)$ & & $53.34 \pm 9.0$ & \\
\hline
\end{tabular}

Table 3. Comparison between female and male groups with positive coronary angiography regarding the presence of hypertension, family history of CAD, hypercholesterolemia, diabetes mellitus and smoking.

\begin{tabular}{lccccc}
\hline Patient groups & Hypertension & FH- CAD & $\begin{array}{c}\text { Hypercholestero } \\
\text { lemia }\end{array}$ & DM & Smoking \\
\hline Female (n 59) & $30 / 59(50.85 \%)$ & $41 / 59(69.49 \%)$ & $21 / 59(35.59 \%)$ & $10 / 59(16.94 \%)$ & $35 / 59(59.32 \%)$ \\
Males (n 116) & $\begin{array}{c}38 / 116(32.76 \%) \\
\text { Significant } \\
\text { P- value }\end{array}$ & $\begin{array}{c}60 / 116(51.72 \%) \\
\text { Significant } \\
(<0.05)\end{array}$ & $44 / 116(37.93 \%)$ & $15 / 116(12.93 \%)$ & $67 / 116(57.76 \%)$ \\
\hline
\end{tabular}




\section{DISCUSSION}

There is a growing interest in research about women with suspected or documented coronary artery disease which, until recently, has been little studied. Coronary artery disease (CAD) is the main cause of death in women, yet almost all studies of coronary heart disease have been done in men. ${ }^{12}$

This study was carried out to assess the effect of gender on angiographic findings on referred patients with chest pain. An important finding of the present study was the presence of normal angiographic findings in $41 \%$ of women, while in only $10.8 \%$ of men. This is statistically significant $(p<0.001)$. The finding is consistent with Ann K Sullivan, et al study, ${ }^{12}$ which showed that the number of negative coronary angiography in women with chest pain is significantly higher than men. The explanation may be that, the evaluation of chest pain symptoms in women has been hampered by attempts to apply a "typical" angina definition (sub-sternal pain, precipitated by emotional stress or physical exertion, relieved within 10 minutes by rest or nitroglycerin) derived predominantly from male populations than female cohorts, as there are substantial 24 differences between women and men in the type, frequency and quality of symptoms noted during their presentation. ${ }^{13}$ And also because the chest pain in women referred for coronary angiography is often non-cardiac in origin. ${ }^{12}$ In some reports, women present less often than men with exertional chest pain symptoms that may be defined as "typical" angina. ${ }^{14}$ Data from the Coronary Artery Surgery Study (CASS) Registry define that many women with chest pain clinically indistinguishable from angina pectoris have no significant atherosclerotic obstruction of their coronary arteries, $50 \%$ of women as contrasted with $17 \%$ of men. This highlights that the clinical history alone is inadequate to diagnose $\mathrm{CHD}$ and coronary risk in women and that objective confirmatory testing is required. ${ }^{15}$ However, women present more frequently than men for the evaluation and are hospitalized more often for chest pain. ${ }^{16}$ The prevalence of obstructive CAD in women is relatively low before menopause. ${ }^{17}$ In the premenopausal woman with normal ovulation, endogenous sex hormones including estrogens are hypothesized as the primary reason for their low incidence of $C A D$ as compared with age- matched men. After menopause, a woman's estrogen level is approximately one-tenth of that during her premenopausal years. ${ }^{18}$ The WISE study results suggest that endogenous estrogen deficiency in young women may be a potent risk factor for CAD. ${ }^{19}$ Estrogens improve the arterial wall response to injury and inhibit the development of atherosclerosis by promoting re-endothelialization, inhibiting smooth muscle cell proliferation, and matrix deposition following vascular injury. ${ }^{20}$ Estrogens also decrease systemic vascular resistance, improve coronary and peripheral endothelial function, and prevent coronary artery spasm in women with and without coronary atherosclerosis. ${ }^{21}$ Interestingly, intracoronary infusion of estradiol improves endothelial function and coronary blood flow in female patients, but not in male patients with coronary artery disease. ${ }^{22}$

We found that the mean age of women with positive coronary angiography was more than that of men with positive test (mean \pm SD $57.49 \pm 8.8$ vs. $53.34 \pm 9.0$ years). This is statistically significant $(p<0.01)$. It was also noted from previous studies that comparable incidence rates are achieved for women who are 10 years older than men, so that CAD rates of 55-year-old men are similar to that of 65-year-old women. ${ }^{23}$ This partly explains the increased mortality observed in women with acute myocardial infarction (AMI). ${ }^{24,25}$

The current study showed that the prevalence of hypertension, which also negatively affects survival, was more in women with coronary artery disease $(50.8 \%)$, than in men $(32.7 \%)$. This was statistically significant $(p<0.05)$. A similar effect was also found by Ann $\mathrm{K}$ Sullivan, et al. $^{12}$ Hypertension is a highly prevalent risk factor that becomes more common in women than in men over the age of 55 years. ${ }^{26}$ In the INTERHEART study, the population attributable risk for hypertension was $36 \%$ in women, indicating that the risk of acute myocardial infarction (AMI) could be reduced by $36 \%$ where hypertension was eliminated as a risk factor. The corresponding figure in men was $19 \%{ }^{8}$

This study also showed that the prevalence of family history of premature CAD is more in women with coronary artery disease $(69.4 \%)$, than in men with coronary artery disease (51.7\%). This was statistically significant $p<0.05$. This finding is consistent with other studies. ${ }^{8,12,26}$ Also we found 
that the prevalence of smoking, diabetes mellitus, and hypercholesterolemia in women with $C A D$ statistically was not significant, in correlation with men who had CAD. These findings are consistent with Ann K Sullivan, et al, ${ }^{12}$ who described similar results.

\section{CONCLUSION}

Standard criteria used to determine the likelihood of coronary artery disease in men are of limited value in women. Women with chest pain referred for diagnostic coronary angiography had significantly more frequently normal coronary artery than men, and the mean age of women with coronary artery disease is significantly higher than men. Therefore, the threshold for referral of young women to the coronary angiography is higher than in men and elderly women. Hypertension and family history of ischemic heart disease were more significantly prevalent in women than in men with coronary artery disease.

\section{RECOMMONDATION}

We recommend to consider the detailed assessment of risk factors stratification based on the Framingham risk score (FRS) to all patients before referral to coronary angiography in future studies as the current study had some limitation regarding this aspect.

Acknowledgement: The authors thank the staff of Mosul Heart Centre in Ibn Sina Teaching Hospital for their kind help and valuable contributions in performing this study.

\section{REFERENCES}

1. Bloomfield $P$, Bradbury A, Crubb NR, Newby DE. Cardiovascular disease. In: Colledge NR, Walker BR, Raiston SH, editors. Davidson's principles and practice of medicine. $21^{\text {st }}$ ed. Edinburgh: Churchill Livingstone; 2010. p. 581-3

2. Andrew DM. Coronary heart disease. In: Ivor JB, Robert CG, Edward JW, editors. CECIL Essentials of medicine. $8^{\text {th }}$ ed. Philadelphia: Saunders; 2010. p. 95-6.

3. Cattern MO, Howard HW, Michael RB, Heidi MC, Rosario VD, Kristin KP, et al. Coronary artery disease in women. In: Medical knowledge self-assessment program (MKSAP). $15^{\text {th }}$ ed. Philadelphia: American College of Physician; 2009. p. 95-6.

4. Detry JR, Kapita BM, Cosyns J, Sottiaux BS, Brasseur LA, Rousseau MF. Diagnostic value of history and maximal exercise electrocardiography in men and women suspected of coronary heart disease. Circulation 1977; 56(5):756-61.

5. Barolsky SM, Gilbert CA, Faruqui A, Nutter DO, Schlant RC. Differences in electrocardiographic response to exercise of women and men: a nonBayesian-factor. Circulation 1979;60:1021-7.

6. Ketch MH, Mohiuddin SM, Lynch JD, Zencka AE, Runco V. Significant sex differences in the correlation of electrocardiographic exercise testing and coronary arteriograms. Amj Cardiol 1975;36:169-73.

7. Grossman W. Complications of cardiac catheterization: incidence, causes, and prevention. In: Grossman W, Baim DS, editors. Cardiac Catheterization, Angiography, and Intervention. $4^{\text {th }}$ ed. Philadelphia: Lea \& Febiger; 1991. P 28-43.

8. Yusuf S, Hawken S, Ounpuu S, Dans T, Avezum A, Lanas $F$, et al. Effect of potentially modifiable risk factors associated with myocardial infarction in 52 countries. Lancet 2004; 36(4):937-52.

9. Daviglus ML, Stamler J, Pirzada A, Yan LL, Garside $\mathrm{DB}$, Liu $\mathrm{K}$, et al. Favorable cardiovascular risk profile in young women and long term risk of cardiovascular and all-cause mortality. JAMA 2004; 292:1588-92.

10. Wilson PW, Kannel WB, Silbershatz H, D'Agostino RB. Clustering of metabolic factors and coronary heart disease. Arch Intern Med 1999; 159:1104-09.

11. Marcus ML, Hiratzka LF, Doty DB, Wright $C B$, Harrison DG, White CW. Coronary obstructive lesions: assessing their physiological significance in humans. Ann Thorac Surg 1986; 42:55-8.

12. Sullivan AK, Holdright DR, Wright CA, Sparrow JL, Cunningham D, Fox KM. Chest pain in women: clinical, investigative, and prognostic features. BMJ 1994; 308(6933): 883-86.

13. Douglas PS, Ginsburg GS. The evaluation of chest pain in women. N Engl J Med 1996; 334:1311-15.

14. Shaw LJ, Gibbons RJ, McCallister B, Mitchell KR, Klein LW, Brindis RG, et al. Gender differences in extent and severity of coronary disease in the ACC National Cardiovascular Disease registry. J Am Coll Cardiol 2002; 39(s2):321-321.

15. Principal Investigators of CASS and Their Associates. National Heart, Lung, and Blood Institute Coronary Artery Surgery Study, American Heart Association Monograph No. 79. Circulation 1981:63 (part II).

16. American Heart Association. Heart Disease and Stroke Statistics. [Online]. 2004. [Cited 2011 Nov 15]; [8 screens]. Available from: URL: http://americanheart. org/downloadable/heart/1072969766940HSStats.

17. Shaw LJ, Heller GV, Travin MI, Lauer M, Marwick T, Hachamovitch $R$, et al. Cost analysis of diagnostic testing for coronary artery disease in women with stable chest pain. J Nucl Cardiol 1999;6:559-69.

18. Paoletti $R$, Cosignani PG, Kenemans $P$. Menopause (problems and interventions in the United States). In: Paoletti R, Cosignani PG, Kenemans P, Samsoe G, Soma M, Jackson AS (editors). Women's Health and Menopause. Norwell, MA: Kluwer Academic Publishers; 1997.p. 9-14.

19. Ponikowski P, Rosano GM, Amadi AA, Collins $P$, Coats AJ, Poole-Wilson PA, et al. Transient autonomic dysfunction precedes ST-segment depression in patients with syndrome X. Am J Cardiol 1996;77:942-47.

20. Mendelsohn ME, Karas RH. Molecular and cellular basis of cardiovascular gender differences. Science 2005;308:1583-87.

21. Leonardo F, Medeirus C, Rosano GM, PereiraWI, 
Sheiban I, Gebara O, et al. Effect of acute administration of estradiol 17 beta on aortic blood flow in menopausal women. Am J Cardiol 1997;80:791-93.

22. Collins $P$, Rosano GM, Sarrel PM, Ulrich $L$, Adamopoulos S, Beale CM, et al.17 beta-estradiol attenuates acetylcholine-induced coronary arterial constriction in women but not men with coronary heart disease. Circulation 1995;92:24-30.

23. Lerner DJ, Kannel WB. Patterns of coronary heart disease morbidity and mortality in the sexes: a 26-year follow-up of the Framingham population. Am Heart $\mathrm{J}$ 1986;111:383-90.
24. Dittrich H, Gilpin E, Nicod P, Cali G, Henning H, Ross J. Acute myocardial infarction in women: Influence of gender on mortality and prognostic variables. Am J Cardiol 1988; 62(1): 1-7.

25. Weaver WD, White HD, Wilcox RG, Aylward PE, Morris D, Guerci A. Comparisons of characteristics and outcomes among women and men with acute myocardial infarction treated with thrombolytic therapy. JAMA 1996 Mar 13;275(10):777-82.

26. Lloyd-Jones D, Adams RJ, Brown TM, Carnethon M, Simone GD, Ferguson TB, et al. Heart disease and stroke statistics; a report from the American Heart Association. Circulation 2010; $121: \mathrm{e} 46-\mathrm{e} 215,25$. 